\title{
Activity Theory as a Potential Framework for Human- Computer Interaction Research
}

\author{
Kari Kuutti
}

\begin{abstract}
In recent years the mainstream framework for human-computer interaction research-information processing cognitive psychology - has come under increasing criticism because of serious problems in applying it in both research and practical design. In a debate within the HCI research community, the capability of information processing psychology has been questioned and new theoretical frameworks considered. This chapter presents an overview of the situation and discusses the potential of activity theory as an alternative framework for HCI research and design.
\end{abstract}

Human-computer interaction has existed for some time as a research domain and gained a reputation as one of the central elements in designing computer applications. Several international journals cover the domain, several international conferences have been held every year, and a huge number of books on the topic have been published. Many, if not most, curricula for software design professionals contain a course in HCI. Given this record, one would assume that there exists a well-established body of harmonious scientific knowledge covering the basic foundation of the discipline. At first sight this belief seems to be valid, because apparently HCI seems to be based on the application of the information processing branch of cognitive psychology: "The chapters in this volume provide an interim report on the project of establishing an applied science of human-computer interaction grounded in the framework of cognitive science" (Carroll 1987).

This harmony is, however, fallacious. Research is not ahead of practice — on the contrary. In fact, a considerable number of researchers have been studying successful solutions in order to understand why they are working. We can take "direct manipulation" here as, an example. This type of interaction was used in practice as early as the sixties and there were working commercial products during the seventies, but it was not before the eighties that researchers started to gain some grasp of the phenomenon (Hutchins, Hollan, and Norman 1986). Still, researchers are unable to provide grounded advice on how such interfaces should be developed. It is also quite difficult to speak about the accumulation of knowledge, a feature usually connected with "mature sciences," because the field consists of fragmented subareas that evince little coherence or connection.

There is a well-known gap between research results and practical design. Bellotti (1988) surveyed English software designers in leading software houses and found that they were not using any results, methods, or recommendations derived from HCI research. Many of these designers were even unaware of the existence of this research. The contents of HCI handbooks aimed at practical designers mostly support that result: although almost all books have a chapter or two about "theoretical background" (usually simple cognitive psychology), it is difficult to find any connection between this material and the "practical guidelines" offered in the balance of these books. Often the only proposal with some theoretical connection is a demand to take into account the limited abilities of the human brain as an information processor. The guidelines then are usually derived from practical experience, with no underlying theory. Thus they suffer from fragmentation, incoherence, and context sensitivity, which needs to be cured by adding guidelines. The largest sets of guidelines already contain of hundreds of recommendations, but with very little internal structure, and they are virtually impossible to use in practice.

Thus it is obvious that there exist many systems where interface has not been an object of explicit design but that nevertheless serve their users well enough to be in continuous use. On the other hand, some of the most remarkable new interfaces have been developed with almost no help from research into cognitive psychology: As Carroll (1991) notes, "Some of the most seminal and momentous user interface design work of the past 25 years made no explicit use of psychology at all." 


\section{RISING CRITICISM}

This state of affairs is obviously not satisfying, and during the late eighties a debate against the use of information processing psychology as the foundation of HCI surfaced, criticizing even the very basic assumptions. (Examples of existing problems and corresponding criticism can be found in Bannon 1990, 1991a, 1991b; Bødker 1990; Ehn 1988; Suchman 1987; Thomas and Kellogg 1989; Whiteside and Wixon 1987; Winograd and Flores 1987.) Both the object and methods of mainstream research have been questioned. Critics would like to add to the research object the users and their actual work tasks. Methodologically the Cartesian ideal of cognitive science - continuing the use of experimental apparatus of laboratory-oriented classical psychology borrowed from natural sciences - has been seen as unable to penetrate the human side of the interface. So now, in the midnineties, we have both the established, cognitive science-based "orthodoxy" and the emerging although diverse "opposition." Although it is certainly too early to speak of a shift in paradigm, we are nevertheless witnessing some kind of crisis in $\mathrm{HCI}$ research. The development of the criticism can easily be studied by comparing two collections of HCI research articles, published only four years apart and both edited by John C. Carroll, a well-known and productive member of the HCI research community. The collections are Interfacing Thought: Cognitive Aspects of Human-Computer Interaction (1987) and Designing Interaction: Psychology at the HumanComputer Interface (1991).

How do these books differ from each other? In the earlier one, the possibilities and prospects of cognitive psychology are mostly seen in a rosy light: " $[\mathrm{HCl}]$ represents a rather unusual opportunity for cognitive science: the opportunity to change future technology by producing an understanding of contemporary technology and thereby perhaps to affect the future directly and constructively" (Carroll 1987 , xiv). The only place where considerable criticism can be found is the polemic commentary by Whiteside and Wixon at the end of the book. They evaluate the benefits of the book from the viewpoint of practical design. Their view is much less optimistic than elsewhere in book, and they are somewhat disappointed with how little help research is giving to practice: "What systems have already been affected by the work described here and similar work that led up to it? In what time frame will the profound influence on interface design be felt?" (Whiteside and Wixon 1987, 355). They also suggest future venues for research, as these subheads in their chapter show: "Could we study HCI in a richer context? Why not tackle real systems? Explore alternatives to studying people as objects to be modeled. Address the political realities of system design."

Four years later, the overall tone had changed considerably. The former critics now have the leading voice: all the authors are disatisfied with the state of affairs and all searching for ways to change it. The alleviation of the problems is sought either from expanding and enriching current cognitive psychology or by exploring totally new approaches. Carroll (1991) writes, "Currently, a reanalysis of HCI as a practical and scientific endeavor is underway. This reanalysis incorporates (at least) these three aspects: (1) reconceiving the relationship between psychological science and HCI design to be one of interaction, (2) integrating richer and more diverse areas of psychology into HCI, and (3) taking the process and products of design more seriously" (74). As part of this effort, several basic assumptions of current HCI research have to be reevaluated: "However, many of the chapters [of the book] advocate and develop more radical proposals. On one hand, they argue that we need to apply approaches to psychology beyond information processing psychology, and perhaps social and behavioral sciences beyond psychology. On the other hand, they argue that information processing psychology itself must be fundamentally enriched as a science base" (5).

What kind of problems and pressures are causing the criticism and movement away from mainstream information processing psychology?

\section{THE NATURE OF PERCEIVED PROBLEMS AND THE DIRECTION OF CHANGE}

Liam Bannon (1991b) presented a set of problematic issues in mainstream HCI research that should be remedied. One of the problems he recognized is expressed in this paper title: "From Human Factors to Human Actors." According to Bannon, one of the characteristic features of the ongoing change is a new vision of human beings as active actors and not only as collections of attributes of cognitive processors, a view not unusual in mainstream cognitive psychology: 
Within the HF (human factors) approach, the human is often reduced to being another system component with certain characteristics, such as limited attention span, faulty memory, etc., that need to be factored into the design equation for the overall human-machine system. This form of piecemeal analysis of the person as a set of components de-emphasizes important issues in work design. Individual motivation, membership in a community of workers, and the importance of the setting in determining human action are just a few of the issues that are neglected. By using the term human actors emphasis is placed on the person as an autonomous agent that has the capacity to regulate and coordinate his or her behavior, rather than being simply a passive element in a human-machine system. (Bannon 1991b, 27-29).

There are also other trends Bannon recognized in recent HCI research. One of them is connected with the problem of using predetermined fixed requirements for product design. The rigidity of the requirements has caused developers to recognize that to understand what is really needed in the situation, users must be consulted. This may be a long, cooperative process, not just an initial asking of some questions. Instead of considering only a single individual, it has been recognized that features of cooperation, communication, and coordination are often vital in the successful performance of tasks. Thus HCI research seeking practical relevance cannot restrict itself to the study of individual acts.

Another issue Bannon identified is the diminishing reliance on laboratory experiments. Restricted and artificial laboratory experiments have been in favor in much of the HCI research, but there is now a tendency to move closer to actual work practices and the demands they pose. "That is, starting with a focus on interface, the subject matter inevitably expands to encompass the complete working circumstances that occasion and motivate the human interaction with the machine" (Henderson 1991, 257).

A third issue for Bannon has been the growing recognition that the actual use of systems is a long-term process that cannot be adequately understood by studying just the initial steps of usage. A large part of HCI research has studied only inexperienced users and usually during a relatively short period. In real life, people develop their skills during longer periods, and this skill-achieving dynamics and its factors have received too little emphasis in research.

Bannon has also found evidence that an emphasis on design has been increasing. Frequently HCI research has concentrated on evaluating some features of existing designs and judging their appropriateness in the situation. Design however, required advice on how to design those features right in the first place, not when it is too late and users are struggling.

The willingness to involve users in the design process has been growing, and that has led to iterative design. When problems in system use seriously surfaced during the eighties, the term "user-centered" arose to denote that designers should study user populations much more carefully than had been the case. Studying users from the "outside" is not enough; users must be involved in the design process itself. Users drawn into the design process however do not usually fully understand all the possibilities offered by information technology. They need some food for thought in order to imagine what the future might be like. This process will lead toward iterative design.

Bannon summarized his findings under the following categories:

- "From Product to Process in Research and Design"

- "From Individuals to Groups"

- "From the Laboratory to the Workplace"

- "From Novices to Experts"

- "From Analysis to Design"

- "From User-Centered to User-Involved Design"

- "From User Requirements Specifications to Iterative Design"

If there is a common denominator for this list, it would perhaps be "better contextuality" because all of the directions discussed aim at taking some aspect of actual use situations into account better. Beside active actors and contextuality, the third major new direction Bannon recognized is the constructive relation between users and systems: "In fact, it is often still the case that computer users need to make some modifications to the system in various ways, tailoring the system before it is truly usable. So in a very real sense users are designers as well" (Bannon 1991b, 29). 
What is behind this kind of change and development? Is there a larger pattern where it would fit?

\section{ENLARGING THE RESEARCH OBJECT}

Jonathan Grudin, who has written about the historical continuity of interface design (1990), found a continuing, phased development "outward" from the hardware: "there is a continuity to the outward movement of the computer's interface to its external environment, from hardware to software to increasingly higher-level cognitive capabilities and finally to social processes" (1). He notes that the phases or steps show the relative importance of the corresponding problems of design and research at any time:

"When we have solved the most pressing problems at one level—or can handle them adequately — human and computer resources are available to work on the next level" (4). Grudin recognized five phases or levels in the development: the interface at the hardware, the interface at the programming task, the interface at the terminal, the interface at the interaction dialogue, and the interface at the work setting. Grudin's view of development is quite similar to that of A. Friedman in his influential book about the development history of computer systems (Friedman 1989). Both see that older problems are never totally solved but remain beside the newer, larger ones; only their relative importance diminishes gradually.

Grudin's paper can be criticized because of its implicit "computer centrism," but the idea of having interface defined at different, coexisting levels is very interesting, because it obviously can relieve some conceptual problems and confusions. Thus it is not surprising that the idea of looking at the interface from several perspectives or levels has been attractive to many researchers (Bentley et al. 1992) and is gaining in popularity (Booth 1989; Clarke 1986; Gaines and Shaw 1986; Kammersgaard 1988; Rasmussen 1986; Smithson and Hirschheim 1990; Stary 1990; Weir 1988). There are, however, some problems with these attempts. Although the use of different perspectives may help in clarifying different approaches to the interface, it does not necessarily help in relating them to each other because of the lack of any unifying background. Even when a hierarchical, layered model has been proposed (Clarke 1986; Bentley et al. 1992; Stary 1990), the result is ad hoc. Although Grudin does not attempt to develop a background framework in his classification paper, the connection of the levels to the historical development is certainly an important step in the right direction.

Bannon and I have continued this line of thinking by using the experience collected in information systems (IS) research as a basis for our own levels of classification (Kuutti and Bannon 1991). IS research has developed a certain consensus that three levels of description are necessary and sufficient to describe information systems, and because interfaces are part of information systems, it might be possible to deal with them using the same classification. We have recognized the following three levels: a technical level, a conceptual level and a work process level. Although the strong connection with the IS research tradition may give our classification some practical credibility, it still suffers from the same problem as the other ones: the lack of a unifying theoretical background. In the paper we connected the growing importance of the work process level in HCI with changes in work practices themselves-with the movement from predetermined work sequences of Tayloristically organized work toward flexibility and self-direction in "neo-Taylorized" work organization.

If we follow the IS tradition and accept the postulate of those three levels-the technical, the conceptual, and the work process - a hypothesis can be made that the problems and debates within HCI research discussed here are due to a change or enlargement of the research object of HCI from one level to another. The nature of this change is a movement between the conceptual and work process levels: conceptually oriented cognitive HCI research is criticized in the debate because it does not take work process aspects properly into account.

Thus we have three broad traditions in HCI research: the technical one, with its roots in "knoband-dial" ergonomics, concentrating human perceptive abilities and motor skills and corresponding features of technical devices; ${ }^{1}$ the conceptual one that has formed the information processing psychology-based mainstream of $\mathrm{HCI}$ research; and the emerging new one searching new frameworks and theories in order to deal with the complexity. What could the role of activity theory be in this situation?

\section{ACTIVITY THEORY: SOME KEY IDEAS}

Both parts of the term activity theory, referring to the Soviet-originated cultural-historical research tradition, are slightly misleading, because the tradition is neither interested in activities in general ${ }^{2}$ nor is it 
a theory, that is, a fixed body of accurately defined statements. ${ }^{3}$ Nevertheless, the term has become established in use, and so we have to cope with it.

Activity theory has long historical roots that are quite unfamiliar to most Anglo-American readers. The oldest background tradition - the eighteenth- and nineteenth-century classical German philosophy, from Kant to Hegel - has remained distant because it opposed the emerging (British) empiricism that later became the foundation of mainstream Anglo-American scientific thought. The classical German philosophy emphasized both developmental and historical ideas and the active and constructive role of humans. Another root-also unfamiliar to many-consists of the writings of Marx and Engels, who elaborated the concept of activity further. ${ }^{4}$ The third source is the Soviet cultural-historical psychology, founded by Vygotsky, Leont'ev, and Luria. ${ }^{5}$

Although the background traditions of activity theory may be unfamiliar, some Anglo-American research traditions have followed similar avenues of thought. Thus it is possible to recognize parallels between activity theory and Dewey's pragmatism (Tolman and Piekkola 1989) and G. H. Mead's symbolic interactionism (Star, forthcoming).

Activity theory originated within Soviet psychology, but today there is an emerging multidisciplinary and international community of scientific thought united by the central category of activity - a community reaching far beyond the original background. ${ }^{6}$ Broadly defined, activity theory is a philosophical and cross-disciplinary framework for studying different forms of human practices as development processes, with both individual and social levels interlinked at the same time. The following discussion highlights the key principles of activity theory.

\section{Activities as Basic Units of Analysis}

Many psychological theories use human action as the unit of analysis. This makes it relatively easy to design laboratory experiments, but the use of isolated actions in analyzing real-life situations outside a laboratory is much less fruitful. The reason is that actions are always situated into a context, and they are impossible to understand without that context (e. g., Suchman 1987). The solution offered by activity theory is that a minimal meaningful context for individual actions must be included in the basic unit of analysis. This unit is called an activity. Because the context is included in the unit of analysis, the object of our research is always essentially collective even if our main interest is in individual actions. An individual can and usually does participate in several activities simultaneously.

\section{History and Development}

Activities are not static or rigid entities; they are under continuous change and development. This development is not linear or straightforward but uneven and discontinuous. This means that each activity also has a history of its own. Parts of older phases of activities often stay embedded in them as they develop, and historical analysis of the development is often needed in order to understand the current situation.

\section{Artifacts and Mediation}

An activity always contains various artifacts (e.g., instruments, signs, procedures, machines, methods, laws, forms of work organization). An essential feature of these artifacts is that they have a mediating role. Relations between elements of an activity are not direct but mediated; for example, an instrument mediates between an actor and the object of doing; the object is seen and manipulated not "as such" but within the limitations set by the instrument (Engeström 1991b). Artifacts themselves have been created and transformed during the development of the activity itself and carry with them a particular culture - $\mathrm{a}$ historical residue of that development. Because of the nature of artifacts, they should be never treated as given. 'The idea is that humans can control their own behavior - not 'from the inside', on the basis of biological urges, but 'from the outside', using and creating artifacts. This perspective is not only optimistic concerning human self-determination. It is an invitation to serious study of artifacts as integral and inseparable components of human functioning" (Engeström 1991a, 12). 


\section{The Structure of an Activity}

An activity is a form of doing directed to an object, and activities are distinguished from each other according to their objects. Transforming the object into an outcome motivates the existence of an activity. An object can be a material thing, but it can also be less tangible (such as a plan) or totally intangible (such as a common idea) as long as it can be shared for manipulation and transformation by the participants of the activity. It is possible that the object and motive themselves will undergo changes during the process of an activity; the object and motive will reveal themselves only in the process of doing. Mediation is carried out by introducing a third, intermediate term, which carries with it the history of the relationship. Thus the (reciprocal) relationship between the subject and the object of activity is mediated by a tool, into which the historical development of the relationship between subject and object thus far is condensed. The tool is at the same time both enabling and limiting: it empowers the subject in the transformation process with the historically collected experience and skill "crystalized" to it, but it also restricts the interaction to be from the perspective of that particular tool or instrument only; other potential features of an object remain "invisible" to the subject (figure 2.1). This structure is too simple to fulfill the needs of a consideration of the systemic relations between an individual and his or her environment in an activity, however, and thus a third main component, community (those who share the same object), has to be added. Two new relationships are then formed: subject-community and community-object. Both of them are also mediated, and thus we have the structure shown in figure 2.2.

This systemic model, which is based on the conceptualization by Engeström (1987), contains three mutual relationships between subject, object, and community. (An activity is actually a systemic whole in the sense that all elements have a relationship to other elements, but all those connections have not been presented in figure 2.2 for the sake of clarity.) The relationship between subject and object is mediated by tools, the relationship between subject and community is mediated by rules, and the relationship between object and community is mediated by the division of labor. These three classes should be understood broadly. A tool can be anything used in the transformation process, including both material tools and tools for thinking. Rules cover both explicit and implicit norms, conventions, and social relations within a community. Division of labor refers to the explicit and implicit organization of a community as related to the transformation process of the object into the outcome. Each of the mediating terms is historically formed and open to further development.

An activity is the minimal meaningful context for understanding individual actions. The famous example of Leont'ev (1978) concerns primitive hunters who, in order to catch game, separate into two groups: catchers and bush beaters. Bush beaters frighten the game toward the catchers. When compared with the goal of hunting - to catch the game, for food and clothing - the actions of the bush beaters in themselves are irrational; they can be understood only as part of the larger system of the hunting activity.

Let us take a more contemporary example of an activity: a software team programming a system for a client. The object is the not-yet-ready system, which should be transformed into a delivered, bug-free application. The team is the community sharing the object, perhaps joined by some representatives of the customer. There is a certain division of labor: between manager and subordinates, between software developers and user representatives, and between the team members. There is a set of rules covering what it means to be a member of this community. Some of these rules may be explicit—set by law, the parent organization, or the team manager - but many of them are most certainly implicit, either as a part of the general working culture or developed as the team works together. Some rules may be constructed for this particular project, for example, how the user representatives of this particular customer shall be treated. In each step of the transformation process, a different set of tools and instruments is used in the transformation process - for example, analysis methods, computers, programming tools, walk-throughs, or rules of thumb. The collection of these tools has a history; it is a result of a process of cumulation and rejection at both company and team level, and additions and deletions to it may occur during any project. Whatever the members of the team do during the project is shaped by the context of activity.

At the same time there is another activity; here the object is the financial status of the software company, and the community consists of team managers and their superiors. Every team manager has tools and tricks designed to keep the project within budget and profitable, and superiors have their own as well. There is a certain division of labor and a certain set of rules - most certainly different from that within a team.

We can imagine a third activity whereby some of the team managers compete against each other for an available position as a department manager. The object "field" is the relative weight of capabilities 
and assets, real or imagined, of each applicant in the eyes of the selection committee. These assets can be transformed by increasing one's own assets or diminishing those of others. Each participating team manager has the relevant tools - excellent financial results from the current project, for example. Again, there is also a division of labor, at least between applicants - those who do the selection and those who can affect the selection. And certainly there is a set of explicit and implicit rules of what constitutes correct behavior in the situation and what does not.

Thus real-life situations always involve an intertwined and connected web of activities that can be distinguished according to their objects. Participation in connected activities having very different objects can cause tensions and distortions (e.g., the position of the team manager in the example: bug-free delivery versus excellent financial results). Psychologically, activity theorists believe that participation in different activities is the major factor in creating consciousness and shaping personality.

\section{Levels of an Activity}

Activities are longer-term formations; their objects are transformed into outcomes not at once but through a process that typically consists of several steps or phases. There is also a need for shorter-term processes: activities consist of actions or chains of actions, which in turn consist of operations, forming the levels in figure 2.3 .

Activities are realized as individual and cooperative actions, and chains and networks of such actions that are related to each other by the same overall object and motive. Participating in an activity is performing conscious actions that have an immediate, defined goal. The actions cannot be understood, however, without a frame of reference created by the corresponding activity. One activity may be realized using different actions, depending on the situation; for example, the software development activity as above consists of different actions depending on how much actual code has to be produced and how much old code can be used, whether parts of applications are purchased from outside, and so forth. On the other hand, one and the same action can belong to different activities, in which case the different motives of activities will cause the action to have a different personal sense for the subject in the context of each activity. For example, the action of reporting on the progress of a project will have a different connotation if it belongs to the activity of internal project management than if it belongs to the activity of competing for promotion-even if the action and its other ingredients are exactly the same.

Before an action is performed in the real world, it is typically planned in the consciousness using a model. The better the model the more successful the action. This phase is called orientation. Thus models and plans are not rigid and accurate descriptions of the execution steps but always incomplete and tentative-resources, in the sense of Suchman (1987). For their part, actions consist of chains of operations, which are well-defined habitual routines used as answers to conditions faced during the performing of the action. Initially each operation is a conscious action, consisting of both the orientation and execution phases, but when the corresponding model is good enough and the action has been practiced long enough, the orientation phase will fade and the action will be collapsed into an operation, which is much more fluent. At the same time a new action is created that will have broader scope and will contain the recently formed new operation as a subpart. On the other hand, when conditions change, an operation can again "unfold" and return to the level of conscious action (so that it is not a conditioned reflex).

This action-operation dynamics and the broadening scope of actions is a fundamentally typical feature of human development. For a person to become more skilled in something, operations must be developed so that one's scope of actions can become broader as the execution itself becomes more fluent. A good example of action-operation dynamics is learning to use a manual gearbox when driving a car. At the beginning, every step in the process (ease the gas pedal, push the clutch pedal, move the gear lever to a new position, release the clutch, give more gas again) is a conscious action that needs planning, sequencing, and decision; many times a hasty look at the gear lever is even necessary in order to move it. But soon these conscious actions begin to transform into operations; the planning and decision making will fade away, resulting in a smooth gear-changing action, far from the clumsiness of the initial attempts. Eventually this gear-changing action will also become an operation in broader corner-turning, lane-changing, and distancemaintaining actions. It will fade from the consciousness.

The border between action and activity is also blurred, and movements are possible in both directions: 
Thus an activity can lose its motive and become an action, and an action can become an operation when the goal changes. The motive of some activity may become the goal of an activity, as a result of which the latter is transformed into some integral activity.... The mobility of the constituents of activity is also manifested in the fact that each of them may become a part of a unit or, conversely, come to embrace previously relatively independent units (for example, some acts may be broken down into a series of successive acts, and, correspondingly, a goal may be broken down into subgoals). (Davydov, Zinchenko, and Talyzina 1983, 36)

The flexibility of the basic concepts makes them useful in describing developmental processes. On the other hand, it also means that it is impossible to make a general classification of what an activity is, what an action is, and so forth because the definition is totally dependent on what the subject or object in a particular real situation is. The classification in figure 2.4 is by no means exhaustive, but it does provide a first grasp of how the levels of the hierarchy could be realized in hypothetical, individual-level activities. There are no firm borders; a software project may be an activity for the team members, but the executive manager of the software company may see each of the projects as actions within his or her real activity at the level of the firm.

One very important feature is that activities have a double nature; every activity has both an external and an internal side. The subject and the object of an activity are in a reciprocal relationship with each other: the subject is transforming the object, while the properties of the object penetrate into the subject and transform him or her. In this internalization, " processes are subjected to a specific transformation: they are generalized, verbalized, abbreviated, and, most importantly, become susceptible of further development which exceeds the possibility of external activity" (Leont'ev 1974, 18).

Activity theory does not accept a dualistic conception of an isolated, independent "mind." The internal side of an activity cannot exist without the external one. A person's internal activity assimilates the experience of humanity in the form in which it manifests itself in the corresponding external activity. "Cognitive processes," says A. R. Luria, “are not independent and unchanging `abilities' or 'functions of human consciousness;' they are processes occurring in concrete, practical activity and are formed within the limits of this activity" (cited by Stetsenko 1993, 43). And Leont'ev (1974) notes, 'It means that a person's mental processes acquire a structure necessarily linked to sociohistorically formed means and modes, which are transmitted to him by other people through teamwork and social intercourse" (19).

Although the triangle model may seem somewhat rigid, it is only for the sake of representational simplicity and convenience. Remember that activity theory considers activities not as given or static but as dynamic. Activities are always changing and developing. Development is taking place at all levels; new operations are formed from previous actions as participants' skills increase; correspondingly, at the level of actions the scope of new actions is enlarging, and totally new actions are being invented, experimented with, and adapted as responses to new situations or possibilities encountered in the process of transforming the object. Finally, at the level of activity the object/motive itself (and the whole structure of activity related to it) is reflected, questioned, and perhaps adapted, reacting to larger changes and other activities.

Because activities are not isolated units but are more like nodes in crossing hierarchies and networks, they are influenced by other activities and other changes in their environment. External influences change some elements of activities, causing imbalances between them. Activity theory uses the term contradiction to indicate a misfit within elements, between them, between different activities, or between different developmental phases of a single activity. Contradictions manifest themselves as problems, ruptures, breakdowns, clashes. Activity theory sees contradictions as sources of development; activities are virtually always in the process of working through contradictions.

What, then, is the relationship between activities and information technology? The answer is not simple, because information technology can support and penetrate activities at all levels. First, a considerable share of all technology in use was developed to automate human operations. According to Leont'ev (1978), in principle all operations can be automated; for example, an automatic transmission automates human gear-changing operations. Information technology is no exception; the major driving force in the development of the first computers was the need to automate human calculating operations, and one of the forces behind the expansion of information technology has been the need to automate administrative data manipulation operations. By automating and substituting human operations, information technology can become part of an activity and vastly expand the scope of actions available to the participants. Automation is the oldest and perhaps best understood way to support activities, but it is not the only way. Information technology can also support actions, in various ways. Information technology 
can serve as a tool in manipulative and transformative actions directed to an object or to a part of it-as with different editors and other symbol-manipulation tools (spreadsheets, drawing, painting, etc.).

Information technology can also help in actions that are directed toward sense making. Zuboff (1988) uses the term informate in characterizing the situation whereby information technology provides a "window" to look at the object of work in order to understand it better. In a sense, managers have been "informated" from the first report ever produced by a system, but an enormous variety of other activities could be supported in this way as well. In Oulu, we have for example been studying how a novice can be helped to learn the ropes more easily by making some elements of a particular activity more visible through information technology (Favorin and Kuutti 1994; Kuutti 1993). Another class of potential actions to be supported are communicative actions between participants. These are directed not toward manipulating or transforming the object but making the activity "run": coordinating or negotiating the motive, or some other facet of the activity.

Finally, at the activity level, information technology can form the matrix of activities; it can be the principal enabler for an activity. At least two different possibilities can be identified. First, information technology may make an activity possible and feasible (e.g., by linking the participants by a network or system). Second, information technology may enable an activity to have an object that would otherwise have been impossible to grasp. In Kuutti and Virkkunen (1994) we discuss a case in which only a computerized "organization memory" enabled health inspectors to grasp and handle new, broader problems as the object of their work activity.

The support possibilities can be illustrated by using the classification in figure 2.5 , where the internal side of activities is compressed under the "actor" heading. This classification does not aim to be a complete explication of the relationships between information technology and an activity, but it illustrates the wide scope and variety of these relations. The classification is somewhat artificial because activities are systemic wholes, and it is impossible to delineate accurately different types in practice. For example, the support types classified as action-level support in the tool area and in the object area overlap because tools are defined as the means of interaction between an actor and the object. Also "supporting sense-making" overlaps naturally with all instances of "making visible" in the same column.

The support given to work activities by traditional information systems seems to match nicely with the first column; practically any such system supports the full range of potential types. It indicates that in the area of work automation, we have already reached a certain level of sophistication, and those types of support are not by any means less important to work activities than more "advanced" or complicated ones. But the further we go from left to right in the classification, the more sparse are the systems designed for giving a particular type of support and the bigger are the challenges of HCI design.

\section{THE POSITION AND POSSIBILITIES OF ACTIVITY THEORY}

The complexity of the field explains a great deal about why the study of HCI has met limited success. Three broad classes of complexity have been recognized: the levels of actions to be supported, dynamics inherent to all levels, and a wide variety of potential support types. Against this background, the "slice" covered by mainstream HCI research is narrow, covering most adequately the area of error-free execution of predetermined sequences of actions. Unfortunately, that is the area where HCI is not crucially needed; humans are so adaptive that eventually the error rate will fall to an acceptable level in most cases, whatever the interface may be. But when we move toward supporting work and sense-making in work, the situation is drastically different; a badly designed interface can paralyze all efforts. The broadening of scope in research and design is both important and difficult, as the parallel debates in different areas of design$\mathrm{HCI}, \mathrm{CSCW}$, and in information systems - show.

What could be the role and contribution of activity theory in these discussions? In this overview I emphasize three perspectives: multilevelness, interaction context, and development.

\section{Multilevelness}

By using activity theory, it is in principle possible to discuss issues belonging to different levels within an integrated framework (figure 2.6). This is certainly a major task, and worth trying in order to overcome the fragmentation that now characterizes the field. 


\section{Interaction in Social Context}

The question of context and sense-making in contexts has recently come to the fore of research. Activity theory and the concept of activity seem to be particularly suited to being used as the starting point in studying contextually embedded interactions. Activity theory contains many features - the recognition of actors, mediation, historicity, constructivity, dynamics, and others-considered essential in recent discussions.

\section{Dynamics and Development}

In HCI, little has been learned about how the formation of new operations, sense-making and creation of new actions, or, ultimately, reconfiguring entire activities, could be supported by information technology. One reason has clearly been a lack of frameworks and theories capable of dealing with developmental and dynamic features of human practices. In this respect, activity theory offers a promising avenue of thought because the ideas of change and development are fundamental to it. It is not possible to cover the whole field of possibilities here, but I will highlight one area where benefits might be accrued rapidly: the potential for using action-operation dynamics in computer interfaces.

Despite the fundamental nature of action-operation dynamics in the development of all kinds of skilled practices, these dynamics have largely been neglected in interface research and development. This is emphasized by the fact that in principle computers are suitable for automating operations even more. In fact, it is quite difficult to find any examples where the dynamics have been properly supported and a "smooth" formation of operations from older actions and the broadening scope of new actions would have been achieved. Certainly many programs have different short-cuts for experienced users. But these do not qualify as a support for action-operation dynamics because usually they are totally different from the original command and thus form a new learning task for the user instead of a collapse of a former action into an operation. It is also true that after a certain level of competence is attained, the broadening scope of actions by combining old operations can be supported to some extent by a powerful operating system such as UNIX with its command files, pipes, and filters. But again, there is no natural path where an operation would develop almost automatically with increasing experience of use.

To support the dynamics properly, it is necessary that the orientation phase of an action be dropped, but that something from the old action remain as a feedback in order to trigger the next possible operation. Fortunately, there is a simple example apposite here: well-known "type-ahead" menus (Shneiderman 1992, 119-120). A type-ahead menu is a chain- or tree-organized menu with an input buffer into which a user can write a selection without having to wait for the menus themselves to appear. When the user knows beforehand all the selections he or she will make when going through the chain or tree of menus, they can be written together as one command at the beginning. Shneiderman provides the following example: "To users of a photo library search system that offered menus with type-ahead, a color slide portrait quickly become known as a CSP and a black and white print of a landscape became known as a BPL. These mnemonics come to be remembered and chunked as a single concept" (Shneiderman 1992, 120). In this example of action-operation dynamics, a whole chain of former actions with a full orientation phase (look at the menu and find the option to be selected) has been collapsed into a single action that has a considerably larger scope than the pieces had. And it is easy to return to the original actions, because they remain permanently as part of the background.

According to activity theory, formation of operations from actions is ubiquitous. This hints that the action-operation dynamics should be a common feature of all computer programs. This raises a series of interesting questions. Because supporting the dynamics is not impossible, why it is so rare? Can this be done in other programs as well? In what kind of use situations might this strategy prove successful? Can a similar effect be realized in a graphical interface? Could it be done over several successive levels, so that an action that has already been formed by collapsing several actions into operations could be collapsed again in the formation of an even more powerful action? The effort to find answers to such questions and to experiment might open a new path for HCI research and design—not an easy one but certainly worth pursuing.

When trying to cope with the interface design problem in all its complexity, it would be enormously helpful if there were a discipline studying, from a design perspective, the problem of how artifacts are utilized in individual and cooperative work in general. Many of the fundamental questions in 
HCI are common to a broad class of artifacts. Unfortunately, such a discipline does not exist, but if there is a shift in emphasis from automating work toward supporting it, the more general problem eventually will be dealt with. Perhaps it is a sort of accident, stemming from the "opaqueness" of computer systems and the need to formulate and formalize whatever is put into them, that HCI research and design have been the first to formulate and attack these problems. As pioneers in the field, we have met with somewhat limited success. There is no reason to be ashamed or depressed, however. Instead we should be proud of being in the forefront and move ahead. There is no risk of becoming too proud; the field will teach us all the humbleness we will ever need.

\section{NOTES}

1. It must be remembered that the publication of some journals actively publishing HCI research started well before the "cognitive turn" in psychology; example are Human Factors and the International Journal of Man-Machine Studies.

2. The term activity does not carry the essential connotation "doing in order to transform something," as do the corresponding German or Russian terms (Tätigkeit and dejatel'nost, respectively).

3. The term can be used in two senses: referring to the original Soviet tradition Leont'ev 1978, 1981; Wertsch 1981) or referring to the international, multivoiced community applying the original ideas and developing them further (Engeström and Punamäki forthcoming). The chapter is based mainly on the "Finnish" interpretation of original ideas, worked out by Y. Engeström and his coworkers (Toikka 1985; Engeström 1987).

4. The origins of the concept of activity lie in German idealistic philosophy, in which Kant, Fichte, and Hegel emphasized the role of mental activity (Tätigkeit) in constituting the relationship between subject and object. This was nevertheless an idealistic-subjective interpretation. The concept of activity was brought into materialistic philosophy by Feuerbach, who emphasized the primary role of objective reality but only as an object of contemplation. The activity concept of Marx was developed as "practical-critical" activity, the central aspect in activity being the transforming of material objects (gegenständliche Tätigkeit) (Klaus and Buhr 1987, pp. 1203-1207).

5. The foundation of activity theory was laid by L. S. Vygotsky during the 1920s and early 1930 s as a culturalhistorical school of psychology. His work was continued by A. N. Leont'ev and A. R. Luria, who developed his ideas and started to use the term activity. A good historical review of the development can be found in Leont'ev (1989).

6. Activity theory is useful and flexible in other disciplines as well, such as education, the social sciences, cultural research, anthropology, and work science (Hildebrand-Nilshon and Rückriem 1988; Engeström and Punamäki forthcoming). The activity theory school is only getting organized, the First International Congress on Activity Theory having been held in Berlin 1986 and the Second Congress in Lahti, Finland, in 1990. From 1988 there has also been a journal, the Multidisciplinary Newsletter for Activity Theory.

\section{REFERENCES}

Bannon, L. J. (1990). A pilgrim's progress: From cognitive science to cooperative design. AI and Society 4:259-275.

Bannon, L. J. (1991). From human factors to human actors: The role of psychology and human-computer interaction studies in system design. In J. Greenbaum and M. Kyng, eds., Design at Work: Cooperative Design of Computer Systems (pp. 25-44). Hillsdale, NJ: Lawrence Erlbaum.

Bannon, L., and Bødker, S. (1991). Beyond the interface: Encountering artifacts in use. In J. M. Carroll, eds., Designing Interaction: Psychology at the Human-Computer Interface. Cambridge: Cambridge University Press.

Bellotti, V. (1988). Implications of current design practice for the use of HCI techniques. In D. M. J. and. R. Winder, eds., People and Computers IV (pp. 13-34). Cambridge: Cambridge University Press.

Bentley, R., Hughes, J. A., Randall, D., Rodden, T., Sawyer, P., Shapiro, D., and Sommerville, I. (1992). Ethnographically-informed systems design for air traffic control. CSCW'92 (pp. 123-129). Toronto: ACM Press. 
Bødker, S. (1990). Through the Interface-A Human Activity Approach to User Interface Design. Hillsdale, NJ: Lawrence Erlbaum.

Booth, P. (1989). An Introduction to Human-Computer Interaction. London: Lawrence Erlbaum.

Carroll, J. M. (ed.). (1987). Interfacing Thought: Cognitive Aspects of Human-Computer Interaction. Cambridge, MA: MIT Press.

Carroll, J. M. (ed.). (1991). Designing Interaction; Psychology at the Human-Computer Interface. Cambridge: Cambridge University Press.

Clarke, A. A. (1986). A three-level human-computer interface model. International Journal of Man-Machine Studies 24:503-517.

Davydov, V. V., Zinchenko, V. P., and Talyzina, N. F. (1983). The problem of activity in the works of A. N. Leont'ev. Soviet Psychology 21(4):31-42.

Ehn, P. (1988). Work-Oriented Design of Computer Artifacts. Stockholm: Arbetslivscentrum.

Engeström, Y. (1987). Learning by Expanding. Helsinki: Orienta-konsultit.

Engeström, Y. (1991a). Activity theory and individual and social transformation. Multidisciplinary Newsletter for Activity Theory (7/8):6-17.

Engeström, Y. (1991b). Developmental work research: Reconstructing expertise through expansive learning. In M. I. Nurminen and G. R. S. Weir, eds., Human Jobs and Computer Interfaces. Amsterdam: North-Holland.

Engeström, Y., and Punamäki, R.-L. (eds.). (forthcoming). Perspectives on Activity Theory. Cambridge: Cambridge University Press.

Favorin, M., and Kuutti, K. (1994). To support learning at work by making work visible through information technology: An activity theory approach. In Interdisciplinary Workshop on Complex Learning in Computer Environments (CLCE'94): Technology in School, University, Work, and Life-Long Education. Finland, University of Joensuu, May 16-19.

Friedman, A. (1989). Computer Systems Development: History, Organization and Implementation. Chichester: Wiley.

Gaines, B. R., and Shaw, M. L. (1986). Foundations of dialog engineering: the development of human-computer interaction. International Journal of Man-Machine Studies, 24:101-123.

Grudin, J. (1990). The computer reaches out: The historical continuity of user interface design. In Proceedings of CHI '90, ACM SIGCHI Conference. Seattle, WA: ACM.

Henderson, A. (1991). A development perspective on interface, design and theory. In J. M. Carroll, ed., Designing Interaction: Psychology at the Human-Computer Interface. (pp. 254-268). Cambridge: Cambridge University Press.

Hildebrand-Nilshon, M., and Rückriem, G. (ed.). (1988). Proceeding of the 1st International Congress on Activity Theory (vols. 1-4). Berlin: System Druck.

Hutchins, E., Hollan, J., and Norman, D. A. (1986). Direct manipulation interfaces. In D. A. Norman and. S. Draper, eds., User Centered System Design: New Perspectives on Human-Computer Interaction. Hillsdale, NJ: Lawrence Erlbaum.

Kammersgaard, J. (1988). Four different perspectives on human-computer interaction. International Journal of ManMachine Studies, 28:343-362. 
Klaus, G., and Buhr, M. eds., (1987). Philosophises Wörterbuch, Band 1-2. Berlin (West): Das Europäeische Buch.

Kuutti, K. (1993). Notes on systems supporting "organizational context"—an activity theory viewpoint. In L. Bannon and K. Schmidt, eds., Issues of Supporting Organizational Context in CSCW Systems (pp. 105-121). ESPRIT Basic Research Project 6225 COMIC. Lancaster: Lancaster University.

Kuutti, K., and Bannon, L. J. (1991). Some confusions at the interface: Re-conceptualizing the "interface" problem. In M. I. and. W. Nurminen G. R. S. Weir, eds., Human Jobs and Computer Interfaces (pp. 3- 19). Amsterdam: NorthHolland.

Kuutti, K., and Virkkunen, J. (1994). Developing teamwork and Organizational Memory: The Case of Finnish Labor Protection Inspectors, no. COMIC-OULU-1-3). Oulu: University of Oulu, Department of Information Processing Science.

Leont'ev, A. N. (1974). The problem of activity in psychology. Soviet Psychology 13(2):4-33.

Leont'ev, A. N. (1978). Activity, Consciousness and Personality. Englewood Cliffs, NJ: Prentice-Hall.

Leont'ev, A. N. (1981). Problems of the Development of the Mind. Moscow: Progress.

Leont'ev, A. N. (1989). The problem of activity in the history of Soviet psychology. Soviet Psychology 27(1):22-39.

Rasmussen, J. (1986). Information Processing and Human-Machine Interaction. An Approach to Cognitive Engineering. New York: North-Hollandh/Elsevier.

Shneiderman, B. (1992). Designing the User Interface: Strategies for Effective Human-Computer Interaction (2nd ed.). Reading, MA: Addison-Wesley.

Star, S. L. (forthcoming). Working together: Symbolic interactionism, activity theory and distributed artificial intelligence. In Y. Engeström and D. Middleton, eds., Communication and Cognition at Work. Cambridge: Cambridge University Press.

Stary, C. (1990). A knowledge representation scheme for conceptual interface design. In A. Finkelstein, M. J. Tauber, and R. Traunmuller, eds., Human Factors in Information Systems Analysis and Design (pp. 157-171). Amsterdam: North-Holland.

Stetsenko, A. P. (1993). Vygotsky: Reflections on the reception and further development of his thought. MNAT(13/14):38-45.

Suchman, L. (1987). Plans and Situated Actions. Cambridge: Cambridge University Press.

Thomas, J. C., and Kellogg, W. A. (1989). Minimizing ecological gaps in interface design. IEEE Software (January):78-86.

Toikka, K. and. E., Y and Norros, L. (1985). Entwickelnde Arbeitsforschung. Theoretische und methodologisce Elemente. Forum Kritische Psychologie 15:5-41.

Tolman, C. W., and Piekkola, B. (1989). Anticipations of activity theory in the critique of the reflex arc concept. MNAT(3/4):43-46.

Weir, G. R. S. (1988). HCI Perspectives on Man-Machine Systems, (Report No. AMU 3588/01S). Scottish HCI Centre, Strathclyde University.

Wertsch, J. W. (ed.). (1981). The Concept of Activity in Soviet Psychology. Armonk, NY: M. E. Sharpe. 
Whiteside, J., and Wixon, D. (1987). Discussion: Improving human-computer interactionn — a quest for cognitive science. In J. Carroll, eds., Interfacing Thought: Cognitive Aspects of Human-Computer Interaction (pp. 353-365). Cambridge, MA: MIT Press.

Winograd, T., and Flores, F. (1987). Understanding Computers and Cognition: A New Foundation for Design. Norwood, NJ: Ablex.

Zuboff, S. (1988). In the Age of the Smart Machine: The Future of Work and Power. New York: Basic Books.

Figure 2.1

Mediated relationship at the individual level.

\section{Figure 2.2}

Basic structure of an activity.

Figure 2.3

Hierarchical levels of an activity.

Figure 2.4

Examples of activities, actions, and operations.

Figure 2.5

A classification of potential ways of supporting activities by information technology.

Figure 2.6

Activity theory areas corresponding to the defined levels of research objects. 